\title{
Formação e produção científica em jornalismo de saúde - Portugal no contexto europeu
}

Sandra Marinho, Felisbela Lopes, Teresa Ruão, Rita Araújo*

Resumo: Uma das variáveis que poderá explicar a qualidade do jornalismo que é produzido sobre o campo da saúde é a formação dos profissionais na área. Por esse motivo, é importante perceber que tipo de oferta existe a esse nível, como se estrutura e a quem se dirige, e que relação existe e é promovida entre a formação e a investigação em jornalismo de saúde. Neste artigo, damos uma perspectiva destas questões para o caso português e avançamos algumas linhas de desenvolvimento para o futuro destes campos.

Palavras-chave: formação em jornalismo, jornalismo da saúde, investigação em comunicação e jornalismo da saúde.

\section{A formação em jornalismo na Europa: traços gerais e o caso da saúde}

Uma das áreas de produção científica sobre a formação em jornalismo pode ser classificada como associada a estudos regionais sobre a questão. Trata-se de trabalhos que, podendo incidir sobre temas diferentes, usam como unidade de análise, ou pelo menos como referência, uma determinada região, sendo os estudos sobre países os mais frequentes. Neste âmbito, destacamos trabalhos como o de Romy Frohlich e Christina Holtz-Bacha (Fröhlich \& Holtz-Bacha, 2003), que procede a uma revisão comparativa das tradições de ensino do jornalismo na Europa e nos Estados Unidos, e, mais recentemente, o de Georgios Terzis (Terzis, 2009).

Fröhlich \& Holtz-Bacha usaram como critério organizador dos países o sistema de ensino de jornalismo que prevalece. $\mathrm{Na}$ "Tradição Académica: ensino de jornalismo nas universidades" incluíam-se a Finlândia, a Espanha, os Estados Unidos e o Canadá; da

\footnotetext{
* Investigadoras do Centro de Estudos Comunicação e Sociedade da Universidade do Minho (marinho@ics.uminho.pt; felisbela@ics.uminho.pt; truao@ics.uminho.pt; rita.manso.araujo@gmail.com). Artigo escrito no âmbito do projecto "A doença em notícia" (financiado pela Fundação para a Ciência e Tecnologia. PTDC/CCI-COM/103886/2008).
} 
“Tradição não académica: ensino de jornalismo em escolas de jornalismo" faziam parte a Itália, a Holanda e a Dinamarca; num grupo que agrega características dos dois anteriores estavam a França, Portugal e a Alemanha; e, finalmente, num último conjunto, o dos países em que a tradição de ensino do jornalismo é “em serviço" (nas organizações e/ou escolas), encontravam-se a Inglaterra e a Áustria. Numa outra secção, apreciavam-se as mudanças no ensino do jornalismo num conjunto de países da Europa de Leste.

Já Georgios Terzis, seis anos mais tarde, recorre a um outro ordenador, os diferentes sistemas de 'media governance' (resultantes das inter-relações entre o mercado, o estado e a sociedade civil e que afectam os média) (2009: 21). São considerados quatro sistemas: o do Norte atlântico (modelo liberal), com a Irlanda e o Reino Unido; o do Norte da Europa (modelo democrático corporativista), com a Áustria, a Bélgica, a Dinamarca, a Finlândia, a Alemanha, a Islândia, o Luxemburgo, a Holanda, a Noruega, a Suécia e a Suíça; o do Mediterrâneo (modelo pluralista polarizado), com o Chipre, a França, a Grécia, a Itália, Malta, Portugal, Espanha e Turquia; e, finalmente, o da Europa de Leste (modelo pós-comunista), com a Bulgária, a Croácia, a República Checa, a Estónia, a Macedónia, a Hungria, a Letónia, a Lituânia, a Polónia, a Roménia, a Eslováquia e a Eslovénia.

Temos aqui patentes duas formas de entender a questão: a formação mapeada a partir do próprio modelo de formação (determinação intrínseca) e a formação ordenada em função do modelo de 'governo dos média', o que pressupõe a ideia de que o ensino do jornalismo também é contextual e é concebido e pensado em função dos modelos de exercício do jornalismo (que dependem em grande parte da perspectiva de cada país sobre o controlo dos média). Relativamente ao conjunto em que se enquadra de forma mais específica o caso português, o dos "países do modelo dos média pluralistas/polarizados do Mediterrâneo" (Terzis, 2009) ${ }^{1}$, podem ser-lhe apontados alguns aspectos comuns. Em termos sucintos, trata-se de países que partilham um conjunto de traços: baixos níveis de circulação de jornais; uma tradição de jornalismo militante (advocacy journalism); a instrumentalização dos média privados; a politização do serviço público de televisão e da regulação; e um desenvolvimento limitado do jornalismo como profissão autónoma (Papathanassopoulos, 2009).

Nestes países, a história do jornalismo está intimamente associada à história política dos média: em alguns há uma forte tradição autoritária e uma experiência algo recente da democracia e da participação política e cívica. Há ainda um conjunto de tendências de desenvolvimento, que podem ser assinaladas: factos e comentários são livremente misturados com notícias; a produção noticiosa interpretativa permanece o modelo dominante de cobertura e estabelece o jornalista como o centro da história; a intervenção estatal é um obstáculo ao desenvolvimento do jornalismo como profissão; e o jornalismo é visto como uma ocupação das elites (Papathanassopoulos, 2009).

Nestes "países do Mediterrâneo" a formação em jornalismo desenvolveu-se relativamente tarde (com um aumento crescente de cursos); há um sistema misto de formação universitária, escolas de jornalismo (stand alone schools) e formação em serviço;

${ }^{1}$ Os países que Terzis (2009) enquadra neste modelo são: Chipre, França, Malta, Grécia, Portugal, Itália, Espanha e Turquia. 
há um número crescente de jornalistas no activo a participarem como professores no ensino, em laboratórios e disciplinas práticas; existem cursos focados na teoria e na investigação, em que as competências práticas são menos importantes; a formação em jornalismo não é considerada um requisito para a indústria dos média e há a ideia de que as competências jornalísticas podem ser aprendidas 'na tarimba'; há uma crescente procura de jornalistas mais bem formados e com um background académico; há uma procura no mercado de formação em serviço adicional; e a crescente existência de licenciados nas redacções não corresponde necessariamente a licenciados em jornalismo (Papathanassopoulos, 2009). Portugal partilha várias destas características, em especial no que respeita à formação em jornalismo.

No que toca especificamente à formação em jornalismo direccionada para o campo da saúde na Europa, podemos tomar por referência a pesquisa realizada pelo projecto HeaRT - Health Reporting Training Project ${ }^{2}$. Este projecto de investigação incidiu sobre todos os países da União Europeia e considerou as seguintes dimensões para análise: o tipo de formação (formal, não-formal e informal); a instituição que oferece a formação, onde se consideraram o sector terciário (ensino superior) e o sector secundário (ensino secundário, centros de formação); a formação contínua (centros de formação em jornalismo); a formação oferecida por outros actores (sindicatos, indústria farmacêutica, ministérios, centros médicos, etc.); programas de formação voluntários, como estágios; o grau a que dá acesso a formação; o público-alvo da oferta (jornalistas e profissionais dos média; médicos e profissionais da área, como enfermeiros e farmacêuticos); e gestores da área da saúde.

As principais conclusões que são retiradas deste projecto podem ser organizadas nos seguintes pontos (HeaRT, 2011) ${ }^{3}$ :

- Há poucos “cursos a tempo inteiro" (full-time study) dirigidos a jornalistas e profissionais dos média. Apesar disto, encontraram-se cursos ao nível do sector terciário na Áustria, República Checa, Alemanha, Portugal, Roménia e Espanha;

- a maior parte dos cursos dura entre quatro e seis semestres. Os curricula começam com uma introdução ao jornalismo e ao trabalho jornalístico, passando pelos diferentes meios, normalmente durante os dois primeiros semestres. $\mathrm{Na}$ Áustria, Alemanha, Portugal e Roménia, a introdução aos aspectos específicos da área da comunicação da saúde começa no segundo ou terceiro semestres;

- os cursos na Alemanha e na Áustria tendem a concentrar-se muito na estrutura e administração dos sistemas de saúde, para depois se concentrarem na análise e discussão dos vários aspectos da comunicação/jornalismo de saúde, nomeadamente questões éticas, investigação e ciências médicas, a influência da indústria farmacêutica e a protecção dos direitos dos pacientes. Na República Checa, Estónia e Portugal, o foco está mais em temas transversais ao curriculum, no estudo sobre

\footnotetext{
${ }^{2}$ http://www.project-heart.eu/

3 As autoras deste texto constituíram a equipa que realizou, como parceira, a investigação no âmbito do projecto em Portugal.
} 
medicina e na exploração dos actos de comunicação nos mass media. Em países como a Roménia e a Espanha (entre outros), encontram-se cursos de jornalismo com disciplinas opcionais de comunicação/jornalismo de saúde;

- no que toca a seminários e cursos de curta duração, na maior parte dos casos identificados tratava-se de um ou dois dias oferecidos por universidades ou organizações profissionais de jornalistas, dirigidos a jornalistas. Regra geral, estes cursos centram-se num tópico do campo da comunicação de saúde, tais como questões éticas, medicina preventiva, gestão de crise nos média, prevenção do VIH e tratamento da diabetes ou novos tratamentos. Em número reduzido, foi encontrada oferta de formação por parte da indústria farmacêutica, hospitais privados, ministérios da saúde e instituições públicas ligadas à saúde;

- quanto a cursos para jornalistas da responsabilidade da indústria farmacêutica, estes foram encontrados na Suíça e, em alguns casos, em países vizinhos como a Itália, a Alemanha e a Áustria. Estes funcionam apenas por convite e estão claramente integrados na estratégia de marketing e relações públicas das empresas. De acordo com os investigadores do projecto, estes cursos funcionam como uma espécie de conferência de imprensa alargada, com acesso a informação exclusiva. O elemento formativo relativo a competências jornalísticas é, pois, reduzido;

- relativamente aos conteúdos e características dos cursos, a análise restringiu-se apenas a quatro cursos e percebe-se que o seu público-alvo seja essencialmente jovens estudantes; isso explica que os planos de estudo contenham elementos de formação básica em jornalismo, sendo os temas específicos da saúde deixados para mais tarde, com seminários em sistemas de saúde, cuidados de saúde, lobbying na saúde ou comunicação da indústria farmacêutica. Quanto às disciplinas/temas comuns, destacam-se: assuntos legais e administrativos na saúde; sistemas de saúde; questões éticas no jornalismo de saúde; assuntos contemporâneos em saúde; introdução aos estudos médicos ou marketing na saúde.

Face aos resultados da investigação, o projecto HeaRT (2011) propõe um conjunto de recomendações sobre matérias que seria importante introduzir na formação em jornalismo de saúde:

- Mudanças e desafios que se colocam actualmente aos sistemas nacionais de saúde na Europa, financiamento da saúde, interdependência, investigação e cuidados de saúde individuais;

- análise avançada sobre o funcionamento dos sistemas de saúde na Europa, filosofias inerentes aos sistemas de saúde, reformas nos sistemas de saúde, actores-chave e stakeholders nos sistemas de saúde, entre outros;

- questões éticas no jornalismo de saúde e responsabilidade dos média face a tentativas de instrumentalização por parte de actores interessados;

- temas contemporâneos (e futuros) como os grandes campos de investigação nas áreas de tratamentos, saúde pública e prevenção, riscos de saúde globais e reforma dos sistemas de saúde; 
- marketing e promoção comercial de assuntos de saúde e o papel dos média e dos jornalistas nas políticas de marketing das empresas, hospitais, médicos e outros stakeholders no sector da saúde;

- materiais de auto-aprendizagem sobre novas ferramentas e formatos e maneira como poderão ser utilizados no jornalismo de saúde, particularmente sobre as ferramentas digitais.

Estas são recomendações que consideramos fazerem todo o sentido para o caso de Portugal, onde, como veremos, há ainda um caminho a fazer na área da formação em jornalismo de saúde, embora, como acabámos de ver, não seja dos casos menos desenvolvidos, quando o consideramos no contexto dos países da UE.

\section{A formação e investigação em jornalismo de saúde em Portugal}

Embora o Ensino Superior seja, de longe, a modalidade mais relevante (se levarmos em conta o volume da oferta) para a formação em jornalismo em Portugal, estamos perante um sistema em que há outros actores, uns mais importantes do que outros. Podemos falar (Pinto \& Marinho, 2009) no envolvimento de outras instituições segundo três modalidades distintas: uma pode ser caracterizada como a da "formação protocolada", um tipo de formação com um certo grau de formalização e consistência no tempo e em termos de oferta; uma segunda modalidade diz respeito a um conjunto de organizações que proporcionam um conjunto de iniciativas, mas fazem-no apenas esporadicamente e englobam a formação dentro das organizações (in house training), como sindicatos ou observatórios; o terceiro dispositivo diz respeito a entidades que oferecem bolsas a serem aplicadas em formação em jornalismo, mas não desenvolvem elas próprias cursos.

Este é um modelo organizador semelhante ao utilizado pelo projecto HeaRT, pelo que vamos adoptá-lo para olhar a formação em jornalismo de saúde em Portugal em articulação com a investigação e produção científica na área, aspectos que consideramos indissociáveis.

\section{a) A investigação sobre a comunicação/jornalismo de saúde}

Em Portugal, a investigação das Ciências da Comunicação em 'comunicação da saúde' é reduzida. Ao nível dos projectos de investigação com alguma extensão temporal, sobressaem os seguintes:

- "Elementos para uma teoria da notícia - O estudo de caso português da mediação jornalística de um problema social - VIH/SIDA" (coordenado por Nelson Traquina): este projecto faz uma análise minuciosa do discurso noticioso da sida (1998-1999);

- "Ser - A saúde em rede" (coordenado por Rita Espanha): a apropriação que o campo da saúde faz das Tecnologias de Informação e Comunicação no contexto da sociedade em rede (2010-2013); 
- “A doença em notícia” (coordenado por Felisbela Lopes): tematização e organização das fontes de informação nos textos noticiosos de imprensa que falam de saúde (2010-2013).

Estes projectos, desencontrados no tempo, não apresentam qualquer linha de continuidade entre eles. Um elege uma doença como centro das investigações (a sida), outro olha para o campo da saúde a partir das plataformas digitais, outro procura explicar o processo produtivo das notícias. Desenvolvidos em centros de investigação geograficamente afastados, os três recolheram financiamento público junto da Fundação para a Ciência e Tecnologia. Destas linhas de investigação, resultaram duas teses de doutoramento:

- Santos, Rogério (2002). Jornalistas e Fontes de Informação - As notícias de VIH-SIDA como estudo de caso. Tese de Doutoramento. Lisboa: Universidade Nova de Lisboa;

- Espanha, Rita (2009). Projectos de Autonomia numa Sociedade em Transição: Os media e a saúde. Tese de Doutoramento. Lisboa: ISCTE-IUL.

Ainda cruzando com estes projectos de investigação e com estas teses, temos dois livros (Santos, 2006; Traquina, N. et al., 2001). Santos (2006) analisa as relações entre jornalistas e fontes de informação. Tendo como referência as notícias sobre a sida, o investigador procura explicar como funcionam as redacções, como trabalham os jornalistas, que agendamento é aí feito. Em Traquina et al. (2001) são reunidos textos de diversos académicos que têm no jornalismo o seu campo de estudo. Apresenta-se aqui uma revisão de literatura sobre as fontes e os jornalistas e faz-se o relato de vários estudos de caso, com destaque para a problemática VIH/sida.

Há ainda a registar um conjunto de outras teses de doutoramento e mestrado que, directa ou indirectamente, abordam as temáticas da saúde e do jornalismo de saúde, ainda que não integradas em projectos de investigação: temos uma tese de doutoramento que trata os discursos sobre o VIH/sida (Pinto-Coelho, 2003) e um conjunto de teses de mestrado sobre a problemática das fontes de informação (Lopes, 2008; Silva, 2008) e sobre a produção noticiosa (Ferreira, 2010; Azevedo, 2009) no campo da saúde.

Desligada de ambientes académicos, a obra Ficheiros Clínicos, da autoria da jornalista Cláudia Borges (2002), reflecte aquilo que se passou no programa com o mesmo nome que a SIC estreou a 9 de Agosto de 1998. Tratava-se de um formato inovador, vocacionado para retratar uma medicina bem sucedida no tratamento de doenças de cidadãos anónimos. Misturava reportagem com debate, estando este formato vocacionado para acompanhar casos de doenças graves, mas bem sucedidos ao nível do tratamento. Cláudia Borges, a jornalista que coordenava e apresentava essas emissões, defendia que seria uma forma de colmatar um vazio ao nível da informação televisiva, dando atenção a uma área que preocupa os cidadãos.

Em termos da produção científica sobre a temática da saúde, podemos identificar, então, três grupos temáticos: a análise da cobertura noticiosa da sida (Traquina, 2000; 
Traquina, 2004; Ponte, s/d; Santos, 2006; Pinto-Coelho, 2003; Pinto-Coelho, 2009); o estudo da relação da saúde com as tecnologias da informação (Espanha, 2010; Espanha \& Cardoso, 2009; Espanha \& Lupiañez-Villanueva, 2009; Espanha, 2009a; Espanha 2009b; Espanha, 2009c; Espanha, 2009d; Espanha, 2008; Espanha \& Cardoso, 2007); a análise do processo produtivo das notícias sobre saúde publicadas na imprensa (Correia, 2006; Ruão et al., 2011; Lopes et al., 2011, Lopes et al., 2010; Marinho et al., 2010).

Ao nível do primeiro tema, o projecto coordenado por Nelson Traquina deu origem a diversos artigos sobre a problemática do VIH/sida e as suas representações na cobertura jornalística, da autoria de Nelson Traquina, Cristina Ponte e Ana Cabrera. Cristina Ponte $(\mathrm{s} / \mathrm{d})$ apresenta resultados parciais de uma análise do discurso da cobertura da sida em dois jornais portugueses, Diário de Notícias e Correio da Manhã, entre 1981 e 2000. A análise, centrada nos títulos das peças jornalísticas, mostra a ideia de ilusão de controlo e segurança, sustentada em fontes oficiais e quase ausência de vozes alternativas, nomeadamente do cidadão comum como portador da doença. Nelson Traquina (2004) apresenta os resultados finais da investigação sobre a cobertura jornalística do $\mathrm{VIH} /$ sida nos jornais diários acima mencionados, cobrindo um período de vinte anos. $\mathrm{O}$ autor refere as diferenças e semelhanças entre um jornal de linha editorial de referência e um outro de linha popular. Em relação às semelhanças, Traquina destaca os mesmos valores-notícia neste tema, particularmente proximidade, infracção, factor tempo, morte e notoriedade do actor do acontecimento. Quanto às diferenças, o autor refere que o DN privilegia a "história" biomédica e interessa-se pela reportagem, enquanto o CM destaca a "história" da epidemia e notícias sobre sexo e celebridades.

Relativamente ao estudo da relação da saúde com as tecnologias da informação e comunicação (TIC), os artigos produzidos por Rita Espanha, alguns dos quais assinados conjuntamente com Gustavo Cardoso, resultam da pesquisa desenvolvida no âmbito de um projecto de investigação acima citado, com o objectivo de identificar e compreender as práticas de informação e comunicação para a gestão individual da problemática da saúde, nomeadamente a construção e desenvolvimento de processos de autonomia individual neste campo.

As tecnologias da informação e comunicação dão autonomia aos indivíduos, relativamente ao seu background social e individual, possibilitando também um escape ao controlo tradicional. Deste modo, enfrentam as contradições da sociedade moderna sem esquecer a relevância das redes de comunicação na construção de novos movimentos sociais. Na sua tese de doutoramento, Rita Espanha (2009d) reflecte sobre o significado das práticas diárias de informação e comunicação na gestão individual dos problemas de saúde e sobre a forma como as TIC são moldadas pelas necessidades individuais e contextos sociais, nomeadamente no caso da comunicação de saúde. A gestão individual da saúde nunca envolveu tanta informação como hoje, havendo uma enorme variedade de informação, oriunda de inúmeras fontes (desde as fontes especializadas e oficiais ao cidadão comum). A autora reflecte sobre as problemáticas relacionadas com o uso da internet para questões de saúde, no caso português.

Temos, finalmente, a linha de investigação que se centra na análise do processo produtivo das notícias sobre saúde publicadas na imprensa. A saúde em geral, e as 
doenças em particular, são um tópico proeminente no campo do jornalismo. Ocupam um espaço substancial na esfera mediática e têm um assinalável impacto junto daqueles que se constituem como fontes de informação e junto das audiências desses textos. No entanto, sabemos muito pouco sobre o respectivo processo de produção noticiosa e sobre o modo como as fontes de informação se organizam e percepcionam o que é publicado. Principalmente em território português. Um grupo de investigadores do Departamento de Ciências da Comunicação da Universidade do Minho está a desenvolver um projecto que elege a 'doença em notícia' como objecto de estudo. Através da análise de três jornais portugueses (Público, Jornal de Notícias e Expresso), pretende-se perceber o processo de mediatização das doenças. Este trabalho de análise implica a identificação da doença mais mediatizada por semestre (ao longo de três anos), bem como uma avaliação da evolução do tratamento jornalístico sobre a doença, essencialmente em torno das fontes de informação.

Ao longo de 2009, por exemplo, uma doença teve amplo destaque nos média: a gripe A. De modo a contribuir para a compreensão da cobertura mediática daquela que a Organização Mundial de Saúde decretou ser uma pandemia, desenvolveu-se um estudo centrado nas fontes de informação citadas nos textos noticiosos sobre este tema. Tendo como referência os artigos publicados no caderno principal de três jornais nacionais escolhidos pela periodicidade e política editorial diferenciadas, procurou-se conhecer, nos 655 artigos que constituíram a amostra, quais foram as fontes ouvidas pelos jornalistas. Deste estudo salienta-se uma “pandemia” que aconteceu, sobretudo, nos média. Nem o número de mortes previstas a nível internacional se confirmou, nem o ambiente de apelo à calma feito a nível nacional se concretizou. Ao longo do corpus de artigos analisados, sobressai um discurso declinado por fontes oficiais que, dentro e fora do país, foram organizando uma comunicação de risco que usou o discurso jornalístico para veicular "pseudo-acontecimentos". Houve uma pandemia mediática que, quando transposta para fora dos média, teve dificuldade em sobreviver, mas que, durante um ano, se manteve em notícia graças à acção de sofisticadas fontes de informação.

Há ainda a referir o interesse das associações científicas nos temas da comunicação e jornalismo de saúde. Em Portugal, anotámos três: a SOPCOM (Sociedade Portuguesa de Ciências da Comunicação), com trabalhos desta área apresentados no âmbito das secções de jornalismo e sociedade e de estudos de televisão; a Associação Portuguesa de Sociologia, com os temas de ciência e conhecimento, de comunicação e de saúde; e a Associação Portuguesa de Geografia.

Dos dados que conseguimos recolher, para os quais não reclamamos exaustividade, é possível perceber que, efectivamente, há um interesse da comunidade científica nas temáticas da saúde, em particular nas áreas que se cruzam com o jornalismo. Entendemos, contudo, que seria importante solidificar as linhas de análise já existentes e dar atenção a outros aspectos relevantes: não há estudos regulares sobre o trabalho jornalístico desenvolvido no âmbito das doenças em geral; não se conhece quem são e como trabalham os jornalistas especializados em saúde; sabe-se pouco sobre a organização das fontes de informação do campo da saúde. 


\section{b) A formação em comunicação/jornalismo de saúde}

Como se pôde perceber da abordagem ao contexto europeu, em Portugal existe formação específica em comunicação/jornalismo de saúde. Para além da oferta no Ensino Superior, e tomando por referência as modalidades que propusemos, encontramos oferta ao nível da "formação protocolada" (CENJOR - Centro Protocolar de Formação Profissional para Jornalistas) e de outras entidades que organizam este tipo de formação de forma esporádica.

No Ensino Superior, encontramos formação ao nível da pós-graduação: um mestrado de Comunicação em Saúde, na Universidade de Lisboa (Faculdade de Medicina), e outro na Universidade Aberta; um curso de pós-graduação em Jornalismo em Medicina e Saúde, na Universidade de Coimbra, em colaboração com o Sindicato dos Jornalistas; e, também na Universidade de Coimbra, em colaboração com o Instituto Nacional de Medicina Legal, um Curso de Introdução às Ciências Médico-Legais e Forenses, em regime de seminário de um ou mais dias, especificamente dirigido a jornalistas e estudantes de jornalismo. Em 2007, o CENJOR organizou um seminário sobre Jornalismo de Saúde e a Ordem dos Médicos; em 2008 e em 2009, realizou outro (com a duração de um dia e com participação por convite) sobre a Medicina e os Média.

Estes são apenas exemplos das iniciativas que são levadas a cabo neste âmbito, mas acreditamos existirem várias outras, sobre as quais não conseguimos ainda apurar dados. Seria, por isso, importante aferir as iniciativas de formação desenvolvidas ao nível dos diversos colégios da Ordem dos Médicos e das várias especialidades médicas, nomeadamente em congressos ${ }^{4}$. Também mereceria uma pesquisa exaustiva a modalidade do "in house training". Ao nível do Ministério da Saúde e suas delegações regionais, foi possível apurar que não existem ainda iniciativas de formação especificamente dirigidas aos jornalistas e aos média. Um aspecto que não contemplámos e será mais difícil de perceber diz respeito às actividades desenvolvidas pela indústria farmacêutica para os jornalistas: que temas são abordados, qual o critério de participação (livre ou por convite), quem são os formadores...

Uma análise aprofundada da oferta seria essencial, para promover uma melhor articulação entre os projectos e a identificação de áreas em falta. Neste âmbito, importaria avaliar os diversos planos de estudo ao nível das temáticas oferecidas, da duração e da natureza do ensino, em termos das estratégias e modalidades adoptadas. Outro aspecto relevante passaria por uma apreciação da relação que existe neste campo entre o ensino e a investigação, nomeadamente procurando perceber de que forma a produção científica (em particular a que decorre de projectos de investigação) tem revertido para formação na área.

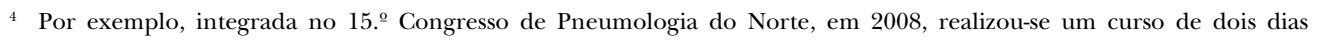
denominado Comunicaşão perante Audiências - Uma competência a adquirir, do qual fazia parte um módulo especificamente vocacionado para a comunicação com os média e com os jornalistas. Haverá certamente iniciativas similares noutros contextos.
} 


\section{Uma área por desenvolver}

O campo da comunicação/jornalismo de saúde está, como vimos, ainda a fazer um caminho em Portugal. Não sendo dos mais desenvolvidos entre os países da UE (como evidenciam os dados do projecto HeaRT), não é também um dos países menos atentos ao fenómeno. Se encararmos as necessidades e limitações que lhe podemos apontar como áreas de desenvolvimento, podemos sugerir algumas possíveis linhas para o futuro:

- Promover uma maior articulação entre os projectos de investigação que existam ou venham a ser aprovados, entre a oferta de formação e entre a investigação e a formação. Não se trata de promover um crescimento em termos de quantidade, mas antes ao nível da qualidade do output. Com esta integração, seria possível, por exemplo, criar bases de dados nacionais sobre a formação e sobre os resultados da investigação, o que, acreditamos, promoveria a qualidade de projectos futuros;

- ao nível da formação graduada, há duas estratégias distintas a considerar: um reforço ao nível da pós-graduação, numa lógica de especialização, e um crescimento da oferta no $1 .^{\circ}$ ciclo, através de disciplinas de opção. Ao nível da formação em serviço, há todo um campo a explorar, particularmente através da colaboração entre as instituições de formação (ensino superior e CENJOR) e as associações profissionais, de jornalistas e profissionais de saúde;

- para que se possa desenvolver a oferta, é crucial compreender que tipo de formação têm e gostariam de ter os profissionais que fazem a cobertura jornalística da saúde;

- é decisivo, antes de mais, que as iniciativas que venham a ser implementadas promovam o contacto e a troca de conhecimento e de experiências entre os profissionais do jornalismo e os da saúde (médicos, enfermeiros, gestores, técnicos).

\section{Referências}

Azevedo, A. P. (2009). “O jornalismo na saúde: uma visão transcontinental”. Tese de Mestrado. Braga: Universidade do Minho.

Borges, C. (2002). Ficheiros Clínicos: Histórias com corpo e alma. Lisboa: Dom Quixote.

Correia, J. C. (2006). A representação jornalística da doença: mecanismo de controlo social e espaço de mediação entre a ciência e a vida quotidiana, BOCC (http://www.bocc.ubi.pt/pag/correia-joao-representacao-jornalistica-da-doenca.pdf).

Espanha, R. (2010). “Tecnologias de Informação e Comunicação na saúde”, in Simões, J. (2010) (coord.) Trinta Anos do Serviço Nacional de Saúde - Um percurso comentado. Coimbra: Almedina.

Espanha, R. e Cardoso, G. (2009). "A saúde electrónica e as práticas de e-health em Portugal”, in JANUS 2009 - Aliança das Civilizações: Um caminho possível e a saúde no Mundo. Lisboa: UAL \& Público.

Espanha, R. \& Lupiañez-Villanueva, F. (2009), "Health and the Internet: Autonomy of the User", in Cardoso, Cheong \& Cole (eds.) (2009), World Wide Internet - Changing Societies, Economies and Cultures, Macau: Ed. University of Macau.

Espanha, R. (2009a). "A Saúde em Rede", in Interface Administração Pública, 49.

Espanha, R. (2009b), Saúde e Comunicação numa Sociedade em Rede - O caso português. Lisboa: Monitor. Espanha, R. (2009c), “A saúde em comunicação”, in Cardoso, G., Cádima, F. R. \& Landerset Cardoso, L. (coord.), Media, Redes e Comunicação: Futuros Presentes. Lisboa: Quimera. 
Espanha, R. (2009d), Projectos de Autonomia numa Sociedade em Transição: Os media e a saúde. Tese de Doutoramento. Lisboa: ISCTE-IUL.

Espanha, R. (2008). Internet and Health Contents. Observatorio (OBS*) [Online] 2:3. Available: http://www. obs.obercom.pt/index.php/obs/article/view/228

Espanha, R. e Cardoso, G. (coords.) (2007). Conteúdos de Saúde Online: Google, www e Blogues, Lisboa: CIES/ISCTE (relatório final).

Ferreira, Ana Isabel (2010). Entendendo o Desentendimento: Contributo para o estudo da comunicação em saúde no processo de encerramento dos blocos de parto em 2006. Lisboa: Universidade Aberta.

Fröhlich, R. \& Holtz-Bacha, C. (eds.) (2003). Journalism Education in Europe and North America - An International Comparision. The Hampton Press Communication Series - Mass Communication and Journalism. New Jersey: Hampton Press.

HeaRT (2011). WP1 Research Report \& Recommendations. HeaRT: Dusseldorf, Germany.

Lopes, I. (2008). Comportamento de Utilização de Fontes de Informação Médica pelos Médicos de Clínica Geral Portugueses. Tese de Mestrado. Lisboa: ISCTE.

Lopes, F.; Ruão, T.; Marinho, S. \& Araújo, R. (2011). “Jornalismo de Saúde e fontes de informação: uma análise dos jornais portugueses entre 2008 e 2010". Derecho a Comunicar, 2.

Lopes, F.; Ruão, T.; Marinho, S. \& Araújo, R. (2011). "Health Journalism: an undeveloped subfield in Portugal”, Health Journalism Training - Heart Meeting, 22 June, University of Coventry - United Kingdom.

Lopes, F.; Ruão, T. \& Marinho, S. (2010). “Gripe A na Imprensa Portuguesa: uma doença em notícia através de uma organizada estratégia de comunicação”. Observatório (OBS*), Vol 4, 4.

Marinho, S.; Lopes, F.; Ruão, T. \& Pinto-Coelho, Z. (2010). Analisando as Notícias sobre Doença: Um primeiro retrato. In Silva et alii, Comunicação, Cognição e Média - Actas do Congresso, Vol. 1, Publicações da Faculdade de Filosofia, Universidade Católica Portuguesa: Braga.

Papathanassopoulos, S. (2009). “The Mediterranean/Polarized Pluralist Media Model Countries”, Georgios Terzis (ed.), European Journalism Education, Bristol, UK: Intellect, pp. 217-230.

Pinto, M. \& Marinho, S. (2009). “The Portuguese Journalism Education Landscape”, Georgios Terzis (ed.), European Journalism Education, Chicago: Intellect/The University of Chicago Press.

Pinto-Coelho, Z. (2003). Drogas em Campanhas de Prevenção: Dos discursos às ideologias. Tese de Doutoramento. Braga: Universidade do Minho.

Pinto-Coelho, Z. (2009) "Figuras da Heterossexualidade na Cobertura Jornalística do HIV/SIDA" in Actas do VI Congresso SOPCOM e IV Ibérico, Lisboa: Universidade Lusófona.

Ponte, C. (2005) “A cobertura de epidemias na imprensa portuguesa. O caso da SIDA" in Actas do III SOPCOM, VI Lusocom e II Ibérico. Volume IV. Covilhã: Universidade da Beira Interior.

Ruão, T.; Lopes, F.; Marinho, S. \& Araújo, R. (2011). Media Relations and Health news coverage: the dialogue on influenza A in Portugal, ECREA Conference - Organizational and Strategical Communication Session, University of Beira Interior, 5-6 May, Covilhã - Portugal.

Silva, Sílvia Patrícia Campos (2008). Fontes de Informação nas Notícias sobre a Queda da Ponte em Entre-os-Rios nos Jornais 'Público' e 'Jornal de Notícias'. Tese de Mestrado. Porto: Fernando Pessoa.

Santos, Rogério (2006). A Fonte não Quis Revelar. Porto: Campo das Letras.

Terzis, G. (ed.) (2009). European Journalism Education. Chicago: Intellect/The University of Chicago Press.

Traquina, N. (2000). "O jornalismo português e a problemática do HIV/Sida: um estudo exploratório". Comunicação e Linguagens, 24.

Traquina, N. et al. (2001) O Jornalismo Português em Análise de Casos. Lisboa: Caminho.

Traquina, N. (2004). "A Sida em notícia: estudo de caso da cobertura mediática no Diário de Notícias e Correio da Manhã". Media \& Jornalismo, 5. 